See discussions, stats, and author profiles for this publication at: https://www.researchgate.net/publication/254873108

\title{
Frequency effects in regular inflectional morphology: Revisiting Dutch plurals
}

Chapter · January 2003

CITATIONS

59

4 authors, including:

Harald Baayen

University of Tuebingen

271 PUBLICATIONS 17,127 CITATIONS

SEE PROFILE
READS

89

Robert Schreuder

Radboud University

147 PUBLICATIONS 5,266 CITATIONS

SEE PROFILE

Some of the authors of this publication are also working on these related projects:

Project Information Theoretic Approaches to Linguistic Structure View project

Project Frequency effects in compound production. View project 
Running head: Dutch inflectional morphology

\title{
Frequency effects in regular inflectional morphology: revisiting Dutch plurals
}

\author{
R. Harald Baayen \\ Interfaculty Research Unit for Language and Speech, \\ University of Nijmegen, The Netherlands \\ James M. McQueen \\ Max Planck Institute for Psycholinguistics, \\ Nijmegen, The Netherlands \\ Ton Dijkstra \\ Nijmegen Institute for Cognition and Information, \\ University of Nijmegen, The Netherlands \\ and \\ Robert Schreuder \\ Interfaculty Research Unit for Language and Speech, \\ University of Nijmegen, The Netherlands
}

Address for correspondence:

R.H. Baayen, Interfaculty Research Unit for Language and Speech, University of Nijmegen, Wundtlaan 1, 6525 XD Nijmegen, The Netherlands Telephone: (+31) 243521510

Fax: (+31) 243521213

e-mail: harald.baayen@mpi.nl 


\begin{abstract}
Six experiments examined how inflected Dutch words are recognized. The auditory lexical decision task was used in Experiments 1, 3, and 5, using, respectively, nouns which take the

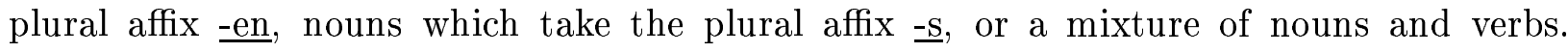
Experiments 2, 4, and 6 were visual analogs of the three auditory experiments. In the first four experiments, the relative frequency of the singular and plural forms of words influenced response latencies to plurals, but not to singulars. In the last two experiments, higher frequency singular nouns and verbs were responded to more rapidly than their corresponding lower frequency plurals. The results suggest that there are independent representations of plural forms for nouns and verbs, in both the auditory and visual modalities, even for forms with fully regular affixes. They argue against the view that storage in the mental lexicon is reserved for irregular forms only.
\end{abstract}




\section{Frequency effects in regular inflectional morphology: revisiting Dutch plurals}

This paper reports a series of experiments that follow up a study of the processing of regular noun and verb plurals in Dutch (Baayen, Dijkstra, \& Schreuder, 1997). That study reported a frequency effect for regular noun plurals in Dutch. It also documented that the summed frequency of the singular and plural form predicted the response latencies to singular forms instead of the frequency of the singular form itself. Finally, that study suggested that there is no frequency effect for verb plurals. The aim of the present paper is to examine whether these frequency effects generalize from the visual to the auditory modality, from the en plural to the $\underline{\text { s }}$ plural, and from one task (lexical decision) to another (progressive demasking).

Frequency effects for regular inflected forms are problematic for theories in which fully regular inflected forms are processed by rule, and in which storage in the mental lexicon is limited to irregular forms (Pinker, 1999; Clahsen, 1999). Clahsen, Eisenbeiss, and Sonnenstuhl (1997) have reported the absence of frequency effects for the $\underline{-s}$ plural in German, which, following Marcus, Brinkmann, Clahsen, Wiese, and Pinker (1995), they describe as the regular default plural in German. Recently, Sonnenstuhl and Huth (2002) have modified this absolute distinction between rule and rote by documenting frequency effects for nondefault semi-regular German plurals (like type I -ㅡ plurals) but not for the default plural $\underline{\text { s. }}$. Another way in which the strict separation of storage and computation has been weakened is the introduction by Alegre and Gordon (1999) of a frequency threshold. Their experiments suggest that storage of regular complex words is restricted to forms with a frequency of at least 6 per million. Given the incompatibility of the findings for German reported by Clahsen and his colleagues and those reported for Dutch by Baayen et al. (1997), and given the fact that their study reports frequency effects for Dutch far below the threshold proposed by Alegre and Gordon, further replication studies on Dutch regular inflections are required.

There are several ways in which the present paper seeks to broaden the empirical support for frequency effects for regular inflected forms in Dutch. First, the original experiments of Baayen et al. (1997) made use of the visual lexical decision task. The present paper reports 
a number of experiments using auditory lexical decision and visual progressive demasking. It is not self-evident that the same pattern of results should emerge for the auditory modality as were found in the visual modality. Unlike the visual input, the auditory input unfolds over time. Other things being equal, this implies that the singular is heard before the plural suffix comes in. Hence, it is not clear whether separate modality-specific representations for plural forms in addition to singular representations would have any added functionality in the auditory modality: The presence of such representations could lead to systematic competition between singular and plural forms.

Second, Laudanna and Burani (1995) and Bertram, Schreuder, and Baayen (2000) have shown that affixes may have very different distributional properties, properties that in turn may differentially affect lexical processing. Thus, it is not clear whether the results observed for the Dutch suffix -en would generalize to other suffixes as well. Therefore, the paper examines the Dutch -s plural in addition to the Dutch -en plural.

Third, to make sure that our results do not depend on the specific task requirements of lexical decision, we have also used progressive demasking as an alternative paradigm. If our previous results are robust, they should be observable irrespective of whether the task requires a lexicality decision.

The remainder of this paper is organized as follows. Experiments 1 and 2 address the frequency effect for noun plurals in -en using auditory lexical decision and visual progressive demasking. Experiments 3 and 4 study the other Dutch plural suffix, $\underline{\text { s}}$, using auditory lexical decision and visual lexical decision. Finally, Experiments 5 and 6 address the claim made by Baayen et al. (1997) that verb plurals do not develop independent lexical representations. This claim is surprising given the autonomy of the frequency effect in cognition in general (Hasher \& Zacks, 1984). As will become clear below, this particular experimental result seems to be limited to visual lexical decision only.

Experiment 1 was an auditory analog of Experiment 1 in Baayen et al. (1997). The relative frequency of occurrence of the singular and plural forms of Dutch nouns was manipulated. The nouns all took the productive plural suffix en (e.g., soep, 'soup', soepen, 'soups'). One set of words, including soep/soepen, was chosen because the singular forms of the words occur more frequently than their plural forms (singular-dominant words). A sec- 
ond set of words were selected which were matched to the first set on the combined frequency of occurrence of their stems (i.e., the summed frequency of occurrence of all tokens containing the words' stems). But, in contrast to the first set of words, the second set consisted of words in which the plural forms occur more frequently than the singulars (plural-dominant words, e.g., wolk, 'cloud', wolken, 'clouds'). In the experiments reported below, we use the factor 'Dominance' to contrast words that differ with respect to the frequency relations between the singular and plural forms, with the aim of tracing the potential contributions of the frequency counts of the singular, the stem, and the plural form to the response latencies.

Baayen et al. (1997) found that visual lexical decision responses were equally fast to singular- and plural-dominant singulars (e.g., soep and wolk). In other words, response latencies to the singulars appeared to be influenced not by their surface frequency (how often the singulars themselves occur) but by their combined stem frequency (on which the two types of words were matched). However, responses to plural-dominant plurals were reliably faster than those to singular-dominant plurals (e.g., responses to wolken tended to be faster than those to soepen). Response latencies to plurals thus appeared to be influenced by the surface frequency of the plural forms. In Experiment 1, we asked whether the same pattern of results would obtain in auditory lexical decision.

Experiment 1: -en in Auditory Lexical Decision

\section{$\underline{\text { Method }}$}

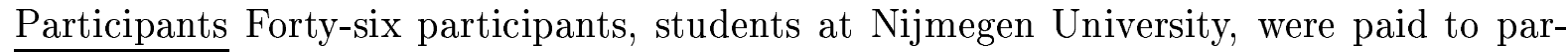
ticipate in the experiment. All were native speakers of Dutch.

Materials For this experiment, we made use of the materials of Experiment 1 of Baayen, Dijkstra, and Schreuder (1997). These materials comprise 93 noun pairs of singulars and plurals, selected from the CELEX-database (Baayen, Piepenbrock \& van Rijn, 1993). We 
used an orthogonal design contrasting Stem Frequency (high versus low), Number (singular versus plural), and Dominance (singular dominant versus plural dominant). For each Stem Frequency condition, we constructed a set of singular dominant and a set of plural dominant pairs. The summed frequency of the singular and plural forms in the singular dominant condition was matched pairwise with the summed frequency of the singular and plural forms in the plural dominant condition.

In the high Stem Frequency condition, we used 21 singular-dominant pairs. The average Stem Frequency of these pairs was 147 per million. The surface frequency of the singular form exceeded that of the plural (singular: 126; plural: 13). The high Stem Frequency condition also included 24 plural-dominant pairs with an average Stem Frequency of 140. For these pairs, the surface frequency of the plural form exceeded that of the singular (singular: 53; plural: 86). In the low Stem Frequency condition, we included 25 singular dominant pairs with an average Stem Frequency of 6 (singular surface frequency: 5, plural surface frequency: 1) and 23 plural-dominant pairs with an average Stem Frequency of 6 (singular surface frequency: 2, plural surface frequency: 4).

The four sets of pairs were matched with respect to length and bigram frequency of the singular and plural nouns. For all pairs, the plural form consisted of the singular form followed by the plural suffix. For the majority of our pairs, no phonological changes in the form of the base were involved. Ten plural forms, however, had a base in which the final obstruent was voiced whereas in the singular form this same obstruent appears as devoiced (4 in the high Stem Frequency, plural dominant condition, 5 in the high Stem Frequency, singular dominant condition, and 1 in the low Stem Frequency, singular dominant condition). No other phonological changes in the segmental form of the words were involved. The materials differ with respect to those of Experiment 1 of Baayen et al. (1997) in only one respect, namely, in that two singular and plural pairs which were different in the visual modality, but were homophonous in the auditory modality, were replaced by unambiguous singular and plural pairs with similar surface frequency and length in phonemes. The materials are listed in Appendix A. ${ }^{1}$

\footnotetext{
${ }^{1} \mathrm{~A}$ variable not explicitly taken into account in this study is family size, the number of derived words and compounds containing the stem as a morphological constituent, see, e.g., De Jong, Schreuder, and Baayen,
} 
In this way, we obtained a stimulus set with 186 test words: 93 singulars and 93 plurals. Figure 1 shows the position of our 93 target nouns in the plane spanned by log singular and log plural frequency, together with the population of monomorphemic nouns with a lemma frequency greater than 0 in the CELEX lexical database. (We added 1 to the frequency counts before taking the logarithm to avoid having to take the logarithm of 0 , which is undefined.) Note the exceptional patterning of the words for which log singular frequency equals 0 (at the left edge of the scatterplot) and the words for which log plural frequency equals 0 (the points at the bottom of the scatterplot). It is here that exceptionally strange and unusual words are located. Such exceptional words were not used in our experiment.

\section{PLACE FIGURE 1 APPROXIMATELY HERE}

For each of these 186 words, we constructed pseudowords by changing one or more phonemes in the base word, such that each real singular was matched with a pseudo-singular and each real plural was matched by a pseudo-stem followed by the plural suffix. We also added 123 filler words and 123 pseudoword fillers derived from these filler words. The set of filler words included adverbs, uninflected monomorphemic adjectives, and a number of singular and plural nouns all of which take the -s plural (30 singulars and 30 plurals of different stems). All pseudowords were phonotactically legal.

We constructed 60 of our pseudo-nouns in such a way that they turned into a pseudoword only at their last segment. These filler pseudowords began with the singular form of a noun but continued with a nonexisting suffix. Some of these pseudowords contained a base that takes the -s plural (e.g., vogelf instead of vogels, the plural of vogel, 'bird') and some contained a base that takes -en (e.g., handef instead of handen, the plural of hand, 'hand'). These items functioned like catch trials, making sure that participants could not safely respond 'yes' to an item before they heard the item's final phonemes.

The complete stimulus set contained 618 experimental items. We divided this set of items over two experimental lists, such that the singular form of each word pair was incorporated in one list and the plural form in the other. In this way we made sure that no participant heard this volume. In this and the following experiments, the cells of the design are approximately matched for family size. Moreover, singulars and plurals of the same stem share exactly the same family size. 
the singular and plural form of the same stem. Thus, 93 different target nouns appeared in each list, either in singular or in plural form, in approximately the same numbers, as well as 123 filler words (either in singular or plural form) together with a similar distribution of nonwords. We pseudo-randomized both lists, with maximally three items of the same type (either word or pseudoword) occurring in sequence, and avoiding semantic associations of any kind between consecutive items. A practice session with 40 practice items (20 words and 20 pseudowords, including singular and plural forms) preceded the experiment itself. The total number of items that a participant was exposed to was 472 .

This material was recorded three times by a native female speaker of Dutch. Subsequently, targets were selected from the auditory word tokens for presentation in the experiment such that the mean length (in ms) did not differ significantly in an analysis of variance within the set of singulars (545 and $543 \mathrm{~ms}$ for the singular-dominant and plural-dominant singulars in the High Stem Frequency condition respectively, and 540 and $554 \mathrm{~ms}$ for the singular-dominant and plural-dominant singulars in the Low Stem Frequency condition) nor within the set of plurals (643 and $666 \mathrm{~ms}$ for the singular-dominant and plural dominant plurals in the High Stem Frequency condition and 660 and $656 \mathrm{~ms}$ for the Low Stem Frequency conditions respectively). Stimuli were also matched for geometric mean biphone frequency.

Procedure We tested our participants in groups of three in individual sound-attenuated booths. We gave them standard lexical decision instructions. Each trial consisted of the presentation of a warning tone $(1 \mathrm{kHz})$ for $200 \mathrm{~ms}$, followed after an interval of $800 \mathrm{~ms}$ by the word or nonword. Stimuli were presented through Sennheiser headphones. Reaction times were measured from word onset. Each new trial was initiated 5 seconds after the previous warning tone. When a participant did not respond within $2500 \mathrm{~ms}$ after the onset of the auditory stimulus, a time-out response was recorded. Three short pauses were included in the experiment: one between the practice and test set, and two during the experiment. After each break, participants continued the experiment when they were ready. The total duration of the experimental session was approximately 50 minutes. 


\section{$\underline{\text { Results and Discussion }}$}

For each participant, the proportion of incorrect responses and missing data was calculated. All 46 participants made less than $10 \%$ errors. We then plotted the distribution of reaction times for all items and all participants, and we removed six extreme individual outlier reaction times (all exceeding $1800 \mathrm{~ms}$, i.e., 5 standard deviations above the grand mean) from the data set. All remaining observations were used to calculate item and participant mean reaction times and error scores. Table 1 shows the mean reaction times and error scores for the different experimental conditions.

\section{PLACE TABLE 1 ABOUT HERE}

The pattern of results closely mirrors that reported in Baayen et al. (1997) for the same materials in the visual modality. We observe a solid main effect of Stem Frequency. High-frequency singulars and plurals elicit shorter response latencies than low-frequency singulars and plurals $(F 1(1,45)=56.27, p<.001, \mathrm{MSe}=3492.73 ; F 2(1,178)=11.77, p<$ .001$, MSe $=8666.48)$. We also observe a main effect of Number: It takes more time to respond to a plural than to a singular $(F 1(1,45)=175.19, p<.001$, MSe $=1802.55$; $F 2(1,178)=22.78, p<.001, \mathrm{MSe}=8666.48 ; p<.001)$. Dominance also emerges as a reliable factor, with plural dominant pairs being responded to faster than singular dominant pairs $(F 1(1,45)=88.49, p<.001, \mathrm{MSe}=2278.59 ; F 2(1,178)=14.50, p<.001$, MSe $=8666.48)$. The main effect of Dominance surfaces in the plural condition (see Table 1): singular dominant plurals have longer response latencies than plural-dominant plurals in each Stem Frequency condition. Not surprisingly, the interaction of Number and Dominance is reliable $(F 1(1,45)=50.25, p<.001, \mathrm{MSe}=1671.66 ; F 2(1,178)=6.60, p<.01$, MSe $=8666.48)$. The interaction between Stem Frequency and Dominance was only significant in the by-participant analysis $(F 1(1,45)=8.02, p<.01$, MSe $=3232.53 ; F 2(1,178)=$ $1.63, p>.20)$. No other interactions emerged as reliable. T-tests show that, just as in Experiment 1 of Baayen et al. (1997), the mean response latencies to plural dominant and singular dominant singulars do not differ reliably: for the high Stem Frequency condition, 
$t 1(90)=0.21, p=0.83 ; t 2(43)=-0.24, p=0.814$, for the low Stem Frequency condition, $t 1(90)=1.58, p=0.12 ; t 2(46)=1.19, p=0.24$. The corresponding analyses of the errors revealed the same qualitative pattern of results in terms of main effects and interactions, with no indications of speed-accuracy trade-offs.

The pattern of results in Experiment 1 is very similar to that in Experiment 1 in Baayen et al. (1997). For singular words in both the high and the low combined stem frequency conditions in both modalities, there were no reliable differences between singular-dominant (e.g., soep, 'soup') and plural-dominant words (e.g., wolk, 'cloud'). Response latencies to singulars are apparently determined by combined stem frequency rather than by surface frequency in the auditory as well as the visual modality. For plural words in both the high and low stem frequency conditions in both modalities, however, latencies to plural-dominant words (e.g., wolken, 'clouds') were reliably faster than those to singular-dominant words (e.g.,

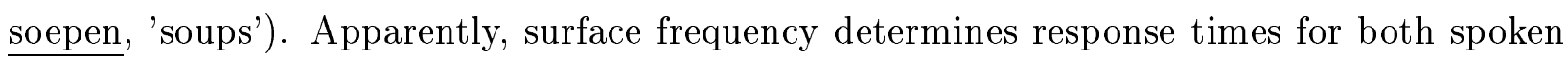
and written plurals. The surface frequency effect in the auditory modality may come as a surprise. In spite of the fact the stem is heard before the suffix comes in, and in spite of the fact that full-form plural representations might well compete with singular representations, Dutch listeners appear to have full-form access representations for regular Dutch plurals.

Auditory form representations for regular plurals probably arise because there are much larger physical differences between singulars and plurals in the spoken domain than in the visual domain. These physical differences could well outweigh any potential processing time advantage that recognition via a morphological parsing procedure might have over a procedure using full-form representations. They might even prevent strong competition between singulars and plurals. In written language, the suffix -en is simply concatenated onto the end of the singular to form the plural. For many Dutch plurals, including all of those tested in Experiment 1, there are no other orthographic changes. ${ }^{1}$ In spoken language, however, there are large phonological changes when the plural suffix -en is added to a noun. As we have already mentioned, in nine of the items in Experiment 1, though the effect is not marked in the orthography, the singular ends with an unvoiced obstruent (e.g., [vant], wand, 'wall'), but with a voiced obstruent in the plural (e.g., [van.dě], wanden, 'walls'). Furthermore, because the -en suffix adds a syllable, there can be resyllabification of medial consonants (as 
in wand/wan.den or soep/soe.pen or wolk/wol.ken, indeed, in all but 9 of the Experiment 1 items). In addition, suffixation of -en leads to large changes in the duration of the first syllable, irrespective of resyllabification. To quantify these changes, we measured the duration of five nouns that resyllabify in the plural (flank, mast, spreuk, spriet and vacht; i.e., the kind of nouns that form the majority of our experimental items). Four native speakers of Dutch recorded five utterances, in isolation, of each of the five singulars and each of the five corresponding plurals. The mean duration of the singulars (538 ms) was longer than that of the stems embedded in the plurals (440 ms; $t 1(3)=2.7, p=.08 ; t 2(4)=15.8, p<.001)$.

At a given speaking rate, therefore, speakers tend to take more time to produce singular forms than they do to say a stem embedded within a plural. These differences should encourage the development of plural access representations. If the plural in the spoken input mismatches with the stored phonological form of the singular, recognition via the parsing route will be slower, and plurals will be more likely to develop independent representations and thus to be recognized via the full-form route.

The next experiment addresses whether the results obtained with visual and auditory lexical decision depend on the task. It might be argued that lexical decision artificially enhances frequency effects in vitro that are not relevant to lexical processing in vivo, due to the decision component that forces participants to distinguish between artificial non-existing words and normal words of the language. Experiment 2 therefore uses visual progressive demasking instead of lexical decision. Participants do not have to respond to pseudo-words in the progressive demasking task.

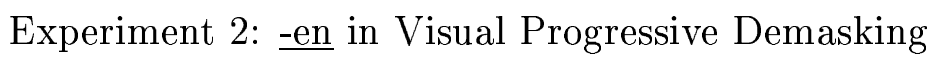

\section{$\underline{\text { Method }}$}

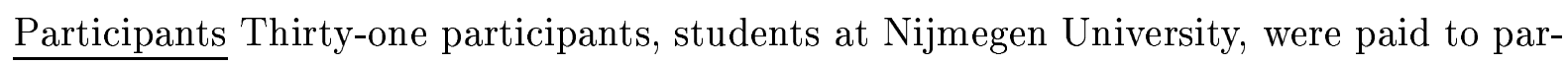
ticipate in the experiment. All were native speakers of Dutch. None had participated in the 
previous experiment.

Materials Only existing words were used in this experiment, no pseudowords were presented. The words were identical to those used in Experiment 1 of Baayen et al. (1997) and to those of Experiment 1 above, with the exception of the two pairs of words that were replaced by non-homophonous words for the auditory lexical decision task. The materials are listed in Appendix A.

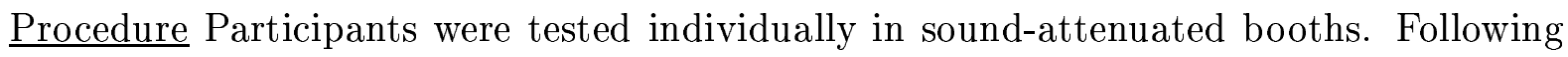
the procedure of Grainger \& Segui (1990) and Grainger \& Jacobs (1996), words were presented in white upper-case 36 points Helvetica letters on a dark background, in alternation with a pattern mask consisting of a series of hash marks of equal length as the words themselves. On each successive cycle, the presentation of the word was increased by $16 \mathrm{~ms}$, and the presentation of the mask was decreased by $16 \mathrm{~ms}$. The total duration of each cycle remained constant at $300 \mathrm{~ms}$. On the first cycle, the mask was presented for $284 \mathrm{~ms}$, and the word for $16 \mathrm{~ms}$. On the second cycle, the words were presented for $32 \mathrm{~ms}$, and so on. There was no interval between cycles. Cycles continued until the participant pressed the response key to indicate that she or he had recognized the word. The screen went blank after response initiation. Response latencies were measured from the beginning of the first cycle. Following each response, participants were asked to write down the word they thought they had recognized.

\section{$\underline{\text { Results and Discussion }}$}

Participants performed this task with a very high degree accuracy, and there were no items that elicited high error scores. The pattern of results for visual progressive demasking is identical to that obtained in Experiment 1 using auditory lexical decision. We again observe main effects of Stem Frequency $(F 1(1,30)=42.7, \mathrm{MSE}=36655, p=.000 ; F 2(1,178)=$ 11.8, $\mathrm{MSE}=97263, p=.001)$, Dominance $(F 1(1,30)=83.8, \mathrm{MSE}=15315, p=.000$; 
$F 2(1,178)=10.5, \mathrm{MSE}=97263, p=.001)$, and Number $(F 1(1,30)=120.2, \mathrm{MSE}=28120$, $p=.000 ; F 2(1,178)=27.1, \mathrm{MSE}=97263, p=.000)$. We also observe exactly the same reliable interaction between Number and Dominance $(F 1(1,30)=28.5, \mathrm{MSE}=30082, p=$ $.000 ; F 2(1,178)=6.4, \mathrm{MSE}=97263, p=.012)$. No other interactions approach significance in both the by-participant and the by-item analyses (Number $*$ Stem Frequency: $F 1(1,30)=$ 4.1, $\mathrm{MSE}=36755, p=0.052 ; F 2<1$; Dominance $*$ Stem Frequency: $F 1(1,30)=4.8$, MSE $=28221, p=0.037 ; F 2(1,178)=1.2, \mathrm{MSE}=97263, p=.270$; for the three-way interaction, $F 1, F 2<1$.) T-tests show that, just as in Experiment 1 and in Experiment 1 of Baayen et al. (1997), the mean response latencies to plural dominant and singular dominant singulars do not differ reliably: for the high Stem Frequency condition, $t 1(60)=0.27, p=0.79 ; t 2(43)=$ $-0.23, p=0.816$, for the low Stem Frequency condition, $t 1(60)=0.70, p=0.50 ; t 2(46)=$ $0.78, p=0.44$. The corresponding analyses of the errors revealed the same qualitative pattern of results in terms of main effects and interactions, with no indications of a speed-accuracy trade-off.

\section{PLACE TABLE 2 ABOUT HERE}

The pattern of results in Experiment 2 was a very close match to that in Experiment 1. In fact, it matches Experiment 1 more closely than the pattern of the corresponding visual lexical decision experiment reported by Baayen et al. (1997). In that experiment, plural dominant plurals in the high stem frequency condition elicited response latencies that were indistinguishable in the mean from the response latencies elicited by the plural dominant singulars. By contrast, in Experiment 1 (auditory lexical decision) and in Experiment 2 (visual progressive demasking), the plural dominant plurals of the high stem frequency condition required significantly more processing time than their corresponding singulars (auditory lexical decision: $t(23)=-2.425, p=0.0236$; visual progressive demasking: $t(23)=-2.55, p=0.0177$; paired t-tests). Apparently, there is a task-specific aspect to the strength of the frequency effect for Dutch plurals in -en, with a high plural frequency leading to shorter response latencies compared to the corresponding singulars in visual lexical decision than in auditory lexical decision or visual progressive demasking. We will return to this difference in the general discussion. 
Taken together, Experiments 1 and 2, and Experiment 1 from Baayen et al. (1997), make a strong case that the recognition of Dutch plurals in both the visual and the auditory modalities make use of full-form representations of those plural forms. Moreover, in both modalities we observe that response latencies to singulars depend on the summed frequencies of the singular and the plural forms.

Although -en is the most common and the most productive plural affix in Dutch, applying to both nouns and verbs, Dutch has an alternative regular plural affix, $\underline{-\mathrm{s}}$, which applies to a significant proportion of the noun vocabulary (31\%), and is also highly productive. In particular, words ending with reduced final syllables almost always take the $\underline{-s}$ plural (see Baayen, Schreuder, De Jong, \& Krott 2002), for further details of the rules governing usage of $\underline{-s}$ and $\underline{-e n}$ ). The next two experiments address the question whether this overall pattern of results generalizes to this second productive plural of Dutch.

Experiment 3: $\underline{-\mathrm{S}}$ in Auditory Lexical Decision

Experiment 3 was modeled closely on Experiment 1, but used plurals in $\underline{\text { s }}$ rather than plurals in -en. The design was simplified, with only the four crucial conditions, singularand plural-dominant singulars, and their matched singular- and plural-dominant plurals; words were again matched on combined stem frequency. However, there was no additional stem-frequency factor because plurals in $\underline{\text { s }}$ tend to be lower-frequency words, which made it impossible to implement a contrast in stem frequency. The materials that we selected display frequency contrasts similar to those in the low stem frequency condition in Experiments 1 and 2. We predicted that there would be no difference in response latencies to singular- and plural-dominant singulars (e.g., anker, 'anchor', and kruimel, 'crumb', respectively), as we did not have any reason to assume that the processing of $\underline{\text {-s }}$ would be fundamentally different from that of -en. Similarly, we also predicted that responses to plural-dominant plurals (e.g., kruimels) would be faster than those to singular-dominant plurals (e.g., ankers). 


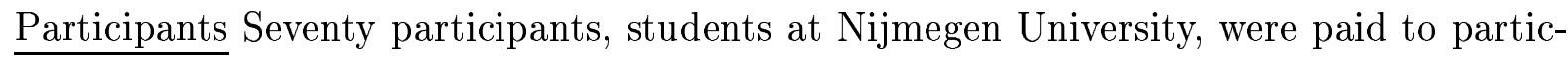
ipate in the experiment. All were native speakers of Dutch. None had participated in the previous experiments.

Materials We selected 21 singular dominant nouns and their corresponding plurals in $\underline{\text { s }}$ from the CELEX lexical database. The mean surface frequency of the singular form was 7.1 per million, the mean surface frequency of the plural form was 2.0 per million, and the stem frequency was 9.1. The corresponding mean frequencies for the 21 plural dominant nouns were $1.8,7.5$, and 9.3 respectively. The target singulars and plurals were divided over two lists, with Number and Dominance approximately balanced, such that no singular and plural form of the same stem appeared in the same list. Each list was augmented with 21 singular filler nouns and 21 plural filler nouns from the same frequency range as the target nouns. All filler plurals were plurals with the suffix -en. We constructed 42 singular pseudowords and 42 plural pseudowords. The plural pseudowords constisted of 21 nonword base words followed by the suffix $\underline{-s}$ and 21 nonword base words followed by the suffix $\underline{\text { en }}$. Of the singular nonwords, 16 became a nonword at word offset. A list of 24 practice items with the same characteristics preceded each list. The target materials are listed in Appendix B. The position of the target materials with respect to the population of monomorphemic nouns taking the $\underline{\text { s }}$ plurals as available in the CELEX lexical database is shown in Figure 2. Except for one noun (stoppel), the extremes of either a zero log singular frequency or a zero log plural frequency are not present in our materials.

\section{PLACE FIGURE 2 APPROXIMATELY HERE}

Procedure The procedure was the same as that used in Experiment 1.

$\underline{\text { Results and Discussion }}$ 
Two words were outliers in that they elicited very high error scores (both exceeding $20 \%$ ). We removed these items and their corresponding singular or plural form from the data set. Removal of these words did not affect the matching of the data with respect to the frequencies of the singular and plural forms (the new mean surface frequency of the singular forms of the singular dominant pairs was 7.3 per million, the new mean surface frequency of the corresponding plural forms was 2.1 per million; the new mean frequencies for the plural dominant nouns were 1.9 and 7.8 respectively). The mean response latencies and error percentages can be found in Table 3. The pattern of results is similar to that observed in Experiments 1 and 2 and Experiment 1 of Baayen et al. (1997): Response latencies to singulars are similar irrespective of Dominance, while singular dominant plurals show longer response latencies than plural dominant plurals and the singular forms. An analysis of variance on the by-participant means revealed reliable main effects of Number $(F 1(1,69)=$ $20.8, M S E=1982.9, p<.0001)$ and Dominance $(F 1(1,69)=12.3, M S E=1138.3, p<$ $.001)$ as well as a significant interaction of these two factors $(F 1(1,69)=57.2, M S E=$ $1484.9, p<.00001)$. A standard analysis of variance on the item means did not reveal any significant factors or interactions. The corresponding analyses of the errors revealed the same qualitative pattern of results in terms of main effects and interactions, with no indications of a speed-accuracy trade-off.

\section{PLACE TABLE 3 ABOUT HERE}

In this study, we have up to this point treated Number as a between-item factor. This amounts to conservative hypothesis testing: The singular and the plural form of the same stem are treated as if they were two completely unrelated words. Given the high significance levels of the by-participant analysis, however, we also performed a less conservative items analysis that took singular and plural forms of the same stem to be two conditions under which this stem was presented. In other words, this analysis treated Number as a withininstead of a between-item factor. The interaction of Number and Dominance now emerges as reliable (Number: $F 2(1,38)=3.6, M S E=2732.1, p=.065$; Dominance: $F 2(1,38)<1$; 
Number*Dominance: $F 2(1,38)=7.4, M S E=2732.1, p<.01)$. This pattern of results also emerges without any data screening (for Number: $F 2(1,40)=3.46, p=0.07$, for Number*Dominance, $F 2(1,40)=4.7, p=0.04, M S E=2978.5)$.

Note that, as observed for the preceding experiments, despite the difference in the surface frequency of the singular forms themselves, the response latencies of the plural dominant and singular dominant singulars did not differ significantly $(t 1(138)=1.42, p=0.16 ; t 2(38)=$ $0.64, p=0.53)$. We conclude that regular plurals in $\underline{-s}$ reveal a surface frequency effect, while singular forms reveal a stem frequency effect.

One reason why the effects with $\underline{-s}$ plurals may be somewhat weaker than those with $\underline{\text { en }}$ plurals is that the physical differences between singulars and plurals in -en are larger than those for singulars and plurals in $\underline{-s}$. The $\underline{\text { s }}$ affix does not add a syllable to the singular form, so there can be no resyllabification, and durational differences should be smaller. If the singular embedded in the plural form thus more closely matches the singular when actually spoken as a singular, recognition via the parsing route should be faster, and recognition should be less heavily dependent on the full-form route.

Nevertheless, the addition of $\underline{\underline{s}}$ produces a complex syllable coda, which should produce some durational adjustments. Durational analyses were therefore carried out (again with four native Dutch speakers, and five repetitions of each word). There were five singulars ending with [1] ( $\underline{\text { rimpel, meubel, gordel, beugel }}$ and $\underline{\text { schakel}})$, five singulars ending with [r] (wimper, veter, polder, cijfer and zwager), and all ten corresponding plurals in $\underline{\text { s. }}$. Singular forms were indeed longer (637 ms, on average) than the durations of the stems embedded in the plurals (e.g., wimper in wimpers; mean $549 \mathrm{~ms}$ ). There was no effect of the final consonant of the singular ([l] vs. [r]). The durational difference was due almost entirely to the second syllable: The durations of the first syllables were, on average, $322 \mathrm{~ms}$ and 300 ms respectively. Spoken word recognition is a rapid and continuous process: Polysyllabic words are accessed on the basis of their initial segments (Marslen-Wilson, 1987; Norris, 1994; Schriefers et al., 1991; Tyler et al., 1988). Thus, there is every reason to suppose that the singular access representation for anker, for example, will be accessed just as rapidly when the first syllable of ankers is heard as when the first syllable of anker is heard. If so, parsing is likely to be quicker for $\underline{\text { s }}$ plurals than for -en plurals, and thus one would expect weaker 
frequency-dominance effects for - s plurals than for -en plurals.

The next experiment checks whether the same pattern of results holds for the visual modality, using standard visual lexical decision.

Experiment 4: $\underline{-\underline{S}}$ in Visual Lexical Decision

$\underline{\text { Method }}$

Participants Sixty-four participants, students at Nijmegen University, took part in the experiment. None had participated in any of the preceding experiments.

Materials We used the same materials as in Experiment 3.

Procedure. Participants were tested in groups of three in sound-proofed booths. They received standard lexical decision instructions. Each trial consisted of the presentation of a fixation mark (asterisk) in the middle of the screen for $500 \mathrm{~ms}$, followed after $50 \mathrm{~ms}$ by the stimulus centered at the same position. Stimuli were presented on Nec Multisync color monitors in white upper-case 36 points Helvetica letters on a dark background. Stimuli remained on the screen for 1500 ms. Time-out occurred $2000 \mathrm{~ms}$ after stimulus onset. The total duration of the experiment was approximately 20 minutes.

\section{$\underline{\text { Results and Discussion }}$}

All participants performed the task with very few errors. Two target words, however, were outliers, with very high error scores (both exceeding 30\%). Together with their corresponding inflectional variants, they were removed from the data set. This removal did 
not affect the matching with respect to the Stem Frequency nor the dominance relations: The new mean surface frequency of the singular forms of the singular dominant pairs was 7.1 per million, the new mean surface frequency of the corresponding plural forms was 2.0 per million; the new mean frequencies for the plural dominant nouns were 2.0 and 8.1 respectively. Table 4 lists the mean response latencies and error scores for the remaining data. Again, we observe the same pattern that emerged for the preceding experiments: singular-dominant and plural- dominant singulars reveal very similar response latencies, whereas singular-dominant plurals reveal longer response latencies than plural- dominant plurals. An analysis of variance by participants supports this conclusion in the form of a reliable main effect of Number $(F 1(1,62)=8.2, M S E=1305, p=.006)$ as well as a reliable Number*Dominance interaction $(F 1(1,62)=8.1, M S E=1446, p=.006)$. The main effect of Dominance was not reliable $(F 1(1,62)=1.4, M S E=1130, p=.246)$. An analysis of variance of the by-item means using Number as a between- items factor did not reveal any significant effects (Number: $F 2(1,76)=1.4, p>0.2$; Dominance: $F 2<1$; Dominance*Number: $F 2(1,76)=1.4, p>.2 ; M S E=2689.7)$. However, as in Experiment 3, we also ran a less conservative analysis of variance in which Number was a within-item factor. In this analysis, the main effect of Number as well as the interaction emerge as reliable (Number: $F 2(1,38)=5.8, M S E=671, p=.021$, Number*Dominance: $F 2(1,38)=5.5, M S E=671, p=.024)$. Without any data screening, the by-item interaction remains reliable while the main effect of Number is now marginally significant (Number: $F 2(1,40)=3.4, p=0.071$, Number*Dominance: $F 2(1,40)=4.75, p=0.035)$. The corresponding analyses of the errors revealed the same qualitative pattern of results in terms of main effects and interactions, with no indications of a speed-accuracy trade-off.

\section{PLACE TABLE 4 ABOUT HERE}

From Experiment 4 we can conclude two things. First, the dominance effect within the plurals suggests that $\underline{-\underline{s}}$ plurals in the visual modality, as in the auditory modality, have independent access representations. Second, the evidence is stronger for orthographic access

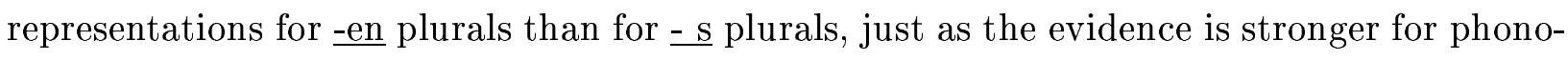
logical access representations for $\underline{\text { en }}$ plurals than for $\underline{\text { s }}$ plurals. In other words, although 
both -en and - s plurals have independent access representations (in both modalities), recognition of -en plurals appears to be more heavily dependent on these representations (and thus less dependent on morphological parsing) than the recognition of $\underline{-s}$ plurals. It is possible that this difference reflects the stronger form-similarities (both phonologically and orthographically) that exist between singulars and plurals in $\underline{-s}$ than that exist between singulars and plurals in en. We return to this issue in the General Discussion.

Experiment 5: Noun and verb plurals in Auditory Lexical Decision

In the final pair of experiments, we turn to a comparison between noun and verb singulars and plurals. Baayen et al. (1997, Experiment 3) compared singular and plural past tense forms of irregular verbs with singular and plural nouns (e.g., vriezen, 'to freeze', which has the past tense forms vroor, 'froze' singular, and vroren, 'froze' plural, was compared with $\underline{\text { gang, }}$ 'corridor', and gangen, 'corridors'). The singular verbs were matched to the singular nouns on surface frequency, and the plural verbs were matched to the plural nouns; the two sets were therefore also matched on combined stem frequency.

Because verbs are almost always singular dominant, it was not possible to include dominance as a factor in the experiment. Irregular verbs were chosen so that exactly the same opposition (no marking for the singular, -en for the plural) could be used for verbs as was used for nouns. Baayen et al. (1997) found a surface frequency effect for the nouns (faster responses to the singulars than to the plurals) but not for the verbs. They argued that this suggested that the plural verb forms do not have independent access representations, and that they are recognized via morphological parsing procedures. Plural verbs were therefore recognized as quickly as their corresponding singulars because both are recognized via the same access representations of the singulars.

Baayen et al. (1997) suggested that this difference between nouns and verbs might be related to the different function of noun and verb plural inflection. For verbs, addition of the plural affix does not change the meaning of the verb; the affix simply acts to supply syntactic processes with information about the external arguments of the verb (contextual inflection, 
Booij, 1993). For nouns, plural inflection may effect subtle changes in meaning (inherent inflection, Booij, 1993). The -en suffix adds to the meaning of the noun in a number of ways, for example, ogen, 'eyes', usually means two eyes, or some multiple thereof, and almost certainly not three eyes or some other uneven number. On the other hand, wolken, 'clouds', usually means many clouds (perhaps even an uncountable number, and almost certainly not two or a multiple thereof). The meanings of noun plurals are not always fully predictable, and this non-predictability might drive the development of separate representations for the plural forms, both at the access level (form representations) and at the central level (semantic representations).

The next two experiments investigated whether the absence of a frequency effect for verb plurals is robust with respect to changes in modality and task. Experiment 5 was an auditory analog of Experiment 3 in Baayen et al. (1997), while Experiment 6 used the same critical materials in visual progressive demasking.

$\underline{\text { Method }}$

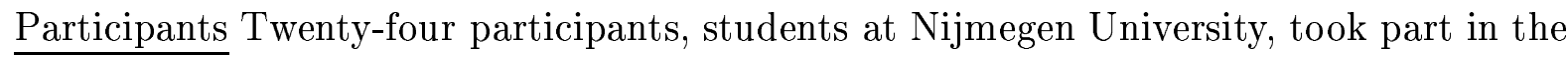
experiment. None had participated in any of the preceding experiments.

Materials and procedure We used the same materials as those reported in Baayen et al. (1997), Experiment 3: 26 nouns and 26 verbs, each of which appeared in the experiment both in the singular and in the plural form. In order to ensure that the en suffix signaled exactly the same opposition between singular and plural on both the nouns and the verbs, the verb materials are restricted to irregular past tense stems, in which vocalic alternation marks the past as opposed to non-past. In the paradigm of the irregular past tense, we find exactly the same opposition in number marking as for nouns: no marking for the singular, and the -en suffix as marker of the plural (e.g., lopen, 'to walk', has the past tense forms liep, first, second, and third person singular, and liepen, first, second, and third person plural). We matched the nouns and verbs for the surface frequency of the singular (27 per million for 
both), for the surface frequency of the plural (7 per million for both), and for the frequency of the stem (34 for both). The materials are listed in Appendix C.

We divided the 104 experimental targets over two lists, such that each stem occurred once in each list, either in the singular form or in the plural form. Each list contained the same number of singular and plural forms. We added the same 130 filler words (nouns, verbs, adverbs, including inflected variants) to both lists. The 182 words were balanced by

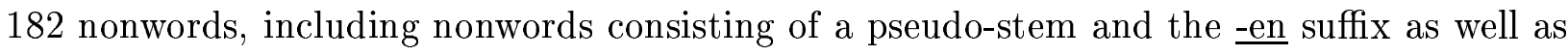
nonwords consisting of a real stem followed by a pseudo-suffix with an initial schwa. These nonwords become nonwords only at word offset. The numbers of singular and plural forms in the experiment were balanced. The experiment was preceded by 40 practice items. The procedure was exactly identical to that of Experiments 1 and 3.

\section{$\underline{\text { Results and Discussion }}$}

The participants performed the task with error rates that are higher than the overall error rates in the preceding experiments. Note, however, that we used low-frequency words in this experiment, and that the error rates are comparable to those of the singular-dominant lowfrequency words in Experiment 1. A number of target words (25), especially plural forms, elicited particularly high error rates (all exceeding 30\%). The data of these words were discarded in the RT analyses. Their removal did not substantially affect the matching (the surface frequency of the singular became 27 for the nouns and 29 for the verbs; the surface frequency of the plural became 8 for the nouns and 9 for the verbs; the frequency of the stem became on average 39 for the nouns and 40 for the verbs). Mean response latencies and error percentages are listed in Table 5.

An analysis of variance revealed reliable effects of Number $(F 1(1,23)=13.96, \mathrm{MSE}=$ $6872.6, p=.0011, F 2(1,75)=12.06, \mathrm{MSE}=8885.7, p=.0009)$ and Word Category $(F 1(1,23)=4.82, \mathrm{MSE}=21508.3, p=.0385, F 2(1,75)=4.14, \mathrm{MSE}=8885.7, p=.0454)$ but no interaction $(F 1, F 2<1)$. In this analysis we removed individual singulars or plurals that elicited many errors. If, as in the preceding experiments, both the singular and plural 
forms are removed together when one of the forms has a high error rate, an analysis of variance again reveals a significant effect of Number $(F 2(1,53)=13.1, p=0.001, M S E=8440)$, a marginally significant effect of Word Category $(F 2(1,52)=3.06, p=0.086, M S E=8440)$, and no interaction $(F 2(1,52)=1.48, p=0.228, M S E=8440)$. A by-item analysis without any data screening revealed exactly the same pattern of results (Number: $F 2(1,100)=$ 27.7, $p=0.000$; Word Category: $F 2(1,100)=4.6, p=0.035$; Number * Word Category: $F 2<1, M S E=11222$ ). The error analysis revealed exactly the same pattern, with no indication of a statistically reliable speed-accuracy trade-off.

These results contrast with those obtained for the visual modality by Baayen et al. (1997) using the same materials. They observed a significant interaction between Number and Word Category: While noun plurals required longer response latencies than their singulars, verb plurals were responded to as fast as their corresponding singulars. In the present experiment, both noun plurals and verb plurals elicit longer response latencies than their singulars.

\section{PLACE TABLE 5 ABOUT HERE}

It might be argued that this discrepancy would disappear if response latencies were measured from word offset. However, an analysis of variance based on RTs measured from word offset revealed a reliable effect for Number only, and no reliable interaction. Interestingly, post-hoc correlations show that a reliable correlation of Surface Frequency and RT is present only when response latencies are measured from word onset (measuring from word onset: $r=-.44, t(77)=-4.3, p=.0001$; measuring from word offset: $r=-.09, t(77)=-.8, p=.4546)$. We conclude that the analysis measuring from word onset is to be preferred, and that we are observing a real dissociation between auditory and visual lexical decision.

Given the similarity of the results obtained with visual progressive demasking and auditory lexical decision in Experiments 1 and 2, it seems likely that a visual progressive demasking experiment using the same materials will also reveal a frequency effect for verb plurals, which would indicate that the dissociation is not simply one of modality.

Experiment 6: Noun and verb plurals in Visual Progressive Demasking 


\section{$\underline{\text { Method }}$}

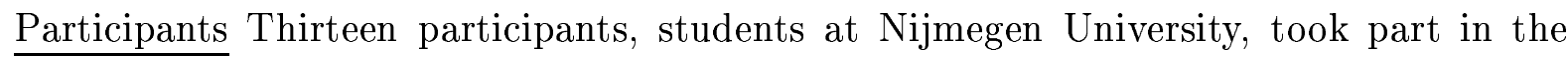
experiment. None had participated in any of the preceding experiments.

Materials The target words are identical to those used in Experiment 5. No filler materials and no pseudowords were added. As in Experiment 5, a participant was exposed to either the singular or the plural form of a given stem, but never to both. A short practice session with 8 items preceded the experiment.

$\underline{\text { Procedure }}$ The procedure was identical to that used in Experiment 2.

\section{$\underline{\text { Results and Discussion }}$}

The participants performed the task with high accuracy, and none of the items elicited high error rates. We therefore included all data points in our analyses. Mean response latencies and error percentages can be found in Table 6. Analyses of variance of the response latencies by participants and by items revealed the same pattern of results as observed for the auditory modality in Experiment 5: significant main effects for Number $(F 1(1,12)=30.6, \mathrm{MSE}=6849.8, p=.0001, F 2(1,100)=13.1, \mathrm{MSE}=34040.9, p=.0005)$ and Word Category $(F 1(1,12)=35.4, \mathrm{MSE}=7811.3, p=.0000, F 2(1,100)=16.5, \mathrm{MSE}=$ $34040.9, p=.0001)$, and no significant interaction $(F(1,12)=1.6, \mathrm{MSE}=9453.8, p=.2282$, $F 2<1$ ). The corresponding analyses of the errors revealed the same qualitative pattern of results in terms of main effects and interactions, with no indications of a speed-accuracy trade-off. We conclude that verb plurals must have independent representations in the visual modality as well, contrary to what Experiment 3 of Baayen et al. (1997) led us to believe. We will return to this issue in the general discussion. 


\title{
PLACE TABLE 6 ABOUT HERE
}

\author{
General Discussion
}

The present study addressed whether the frequency effects for noun and verb plurals reported by Baayen et al. (1997) are robust with respect to changes in modality, task, and suffix. That study suggested that the stem frequency (the summed frequency of the singular and the plural form) is the predictor of response latencies in visual lexical decision for noun singulars, that the frequency of the plural form is the predictor for response latencies for noun plurals, and that there is no separate plural frequency effect for verb plurals.

Experiments 1 and 2 of the present study replicated the stem and plural frequency effects for the -en plural using auditory lexical decision and visual progressive demasking. Experiments 3 and 4 similarly replicated these effects for a second Dutch plural suffix, $\underline{-\underline{S}}$. The main pattern that emerges from these experiments is that for noun singulars the summed frequency of the singular and plural forms is the predictor of the response latencies, and that for noun plurals the frequency of the plural form is the key predictor. Experiments 5 and 6 showed that, in contrast to the earlier findings with visual lexical decision, there was also a plural frequency effect for verbs in auditory lexical decision and in visual progressive demasking. Across all experiments in the present study, plural frequency emerges as a significant predictor of response latencies.

We interpret our results in the context of the parallel dual route model of Baayen et al. (1997). That is, we assume that noun plurals are processed on the basis of representations for the stem, the plural suffix, and the plural form itself. These representations are activated in parallel, with the plural form and the parse of stem and affix providing two routes for recognition. In this model, the stem frequency effect for singular nouns is explained by assuming that the resting activation level of the access representation of the singular is a function of the summed frequencies of its inflectional variants. The plural frequency effect arises from a combination of the two routes working in parallel, with the full forms of plurals contributing more to the recognition in the case of nouns with high-frequency stems than in the case of nouns with low-frequency stems. 
In what follows, we discuss the main three new findings of this study: the difference in magnitude of the plural frequency effects across tasks, the difference in the magnitude of the frequency effect for the plural suffixes $\underline{-\underline{s}}$ and $\underline{-e n}$, and the dissociation between the visual lexical decision on the one hand and auditory lexical decision and progressive demasking on the other hand with respect to the plural frequency effect for verbs.

The plural frequency effects observed in the auditory modality and in visual progressive demasking were smaller than those in visual lexical decision. High-frequency plural-dominant plurals like wolken ('clouds') were responded to as rapidly as plural-dominant singulars like $\underline{\text { wolk }}$ in visual lexical decision, even though they have quite different surface frequencies, but not in the other two tasks. We think that the difference in the magnitude of the frequency effect between visual and auditory lexical decision is due to differences in the way in which singulars are embedded in plurals in the two modalities. In the visual modality, the singular is fully present in the plural form. Consequently, recognition of the plural can benefit fully from the operation of the parsing route. In the auditory modality, however, singulars are not properly embedded in plural forms: The stem in a plural tends to be shorter in duration than a singular. The parsing route is therefore likely to contribute less to plural recognition in this modality.

The difference in the strength of the frequency effect between visual lexical decision and progressive demasking might be due to a response competition effect in progressive demasking. In visual lexical decision, both routes converge on the lexicality of the stimulus, i.e., both routes lead to a yes-response. However, in progressive demasking, a unique identification response must be made. Participants must choose between the singular and the plural form, slowing down identification latencies for the plural forms. Note, however, that even if there is response competition in progressive demasking, the difference between singular-dominant and plural-dominant plurals observed in that task supports the hypothesis that regular full forms are stored in the mental lexicon.

The plural frequency effects observed for the -en plural were greater than those observed for the $\underline{-s}$ plural. This difference may arise as a consequence of the difference in which the singular form is present in the plural form. In the visual modality, the singular form accounts for on average 4.29 letters of the on average 6.29 letters of the plural form for 
the nouns taking -en: $68.2 \%$. For nouns taking $\underline{-\mathrm{s}}$, the corresponding percentage equals $5.59 / 6.59=84.8 \%$, showing that singular and plural are more similar in the case of $\underline{\text { s }}$ than in the case of $\underline{\text { en. }}$. In the auditory modality, the difference between the singular and plural forms may already be carried by the duration of the first syllable in the case of $\underline{\text { en }}$ plurals, while for $\underline{-s}$ plurals such durational differences appear only in the second syllable. In both modalities, it therefore appears that the singular (or stem) of a plural in $\underline{-s}$ has a better chance of being activated than the singular (or stem) of a plural in -en: It receives more bottom-up support. We think that the comparatively large bottom-up support for the stem of plurals in $\underline{-s}$ is advantageous for a recognition procedure based on morphological parsing and disadvantageous for one based on access via full-form representations. This may underlie the observed reduced frequency effects for plurals in $\underline{-s}$.

The difference in the magnitude of the frequency effect for the two Dutch plural suffixes provides further support for the claim initially advanced by Laudanna and Burani (1995) and subsequently by Bertram, Schreuder, and Baayen (2000) that affix-specific properties must be taken into account for a proper understanding of morphological processing.

Finally, the absence of a plural frequency effect for verbs in visual lexical decision and its presence in auditory lexical decision and progressive demasking requires an explanation. We think that such an explanation must incorporate the fact that noun plurals involve inherent inflection while verb plurals instantiate contextual inflection (Booij, 1993). After all, the visual and acoustic properties of verbs do not differ, to our knowledge, from the corresponding properties of nouns. The two kinds of plurals, however, do differ with respect to their semantics. Noun plurals may well have their own semantic representations at the central level in addition to form representations at the access level. By contrast, verb plurals probably have just a single semantic representation at the central level. Since the auditory lexical decision experiment and the progressive demasking experiment reveal a plural frequency effect for verbs, we have to assume that plural verbs have their own form representations at the access level as well. ${ }^{2}$ The singular and plural form representations of verbs, however, provide access to one and the same central semantic representation. This difference between

\footnotetext{
${ }^{2}$ Possibly, the multiple homonymy of the - en suffix is a contributing factor here, see, e.g., Baayen et al. (1997) Bertram, Laine, Baayen, Schreuder, \& Hyönä (1999).
} 
nouns and verbs is in line with the possibility for noun plurals to serve as input for further word formation, while this possibility does not exist for finite verb forms (Booij, 1993). We think that in lexical decision, a task that is sensitive to semantics, the response latencies are based to a large extent on the activation of central representations becoming available. In the case of verbs, but not in the case of nouns, there is only one semantic representation to be activated, leading to response latencies that do not differ between the singular and the plural verb forms.

We have seen that in auditory lexical decision the acoustic signal of the stem in the plural form is reduced in length, and we have argued that this may provide information that a plural form is being processed. This would mean that the singular form can be deactivated fairly quickly, with as consequence that the contribution of the singular form to the activation level of the lemma representation of the plural in the case of nouns and to the undifferentiated lemma in the case of verbs will be reduced or even absent. Since for both nouns and verbs only the plural form representation contributes effectively to the activation at the lemma level, the observed identical effects of plural frequency for nouns and verbs follow. In the case of visual progressive demasking, the observed difference between the verb singulars and plurals may be due to the presence of access representations for plurals in the visual modality (as in the auditory modality). Part of the effect may, however, be due to response competition specific to visual progressive demasking, as explained above in the context of the reduced plural frequency effect for nouns.

The surface frequency effects for regular plurals that we have observed across all six experiments challenge full-parsing models, in which regularly-inflected words are always recognized on the basis of their morphological constituents (Clahsen, 1999; Pinker, 1999); such models do not predict surface-frequency effects for plurals. The observed plural frequency effect argues against the idea that storage in the mental lexicon is restricted to irregular complex words, and that regular complex words are always processed by rule, what Bybee (2001) aptly calls the rule/list fallacy. One the other hand, these surface frequency effects are consistent with the parallel dual route model of Baayen et al. (1997), as argued above. For linguistic and experimental evidence for the regularity of both the $\underline{-s}$ and the $\underline{\text { en }}$ plurals, see Baayen et al. (2002). 
The absence of surface frequency effects for singulars, in combination with an effect of stem frequency (Experiments 1-4), is also accountable for in the parallel dual route model. These findings, however, challenge full-listing models (e.g., Butterworth, 1983) and the AAM cascaded dual-route model (Caramazza et al., 1988; Laudanna \& Burani, 1985). Both of these types of model predict surface frequency effects for both singulars and plurals. The full-listing model proposed by Giraudo and Grainger (2001), however, provides a framework in which the stem frequency effect for singular nouns can be explained.

The absence of surface frequency effects for singulars also challenges the model of lexical access proposed by Taft $(1979 ; 1988 ; 1994)$. In this model, all words are recognized via a morphological parsing procedure; parsing precedes the retrieval of full-form representations in the central lexicon. The model predicts surface frequency effects for both singulars and plurals (due to the sensitivity of the central representations to surface frequency). The model also predicts combined stem-frequency effects, since words sharing the same stem will be recognized via the same access representation of that stem. Taft (1979) found support for this model in a study of English visual word recognition, observing surface frequency effects for both uninflected and inflected words. Sereno and Jongman (1997) also found weak surface frequency effects for singular English nouns. In contrast to English, a study of singulars and plurals in Italian (Baayen, Burani, \& Schreuder, 1996) found that response latencies to singulars were determined by stem frequency and not by surface frequency, paralleling the present results. It is unclear to us why the data for English with respect to frequency effects for singulars do not converge with those for Dutch and Italian.

The observation of plural frequency effects in English, Italian, and Dutch, and within Dutch for two different plural suffixes across the auditory and visual modalities, in two different tasks, suggests that we are tapping into a phenomenon that is neither language-specific, nor task-specific, nor affix-specific. Our data show that there are independent representations of plural forms for nouns and verbs, in both the auditory and visual modalities, even for forms with fully regular affixes. Our data provide further evidence against the view that storage in the mental lexicon is limited to irregular forms only. 
References

Alegre, M. \& Gordon, P. (1999). Frequency effects and the representational status of regular

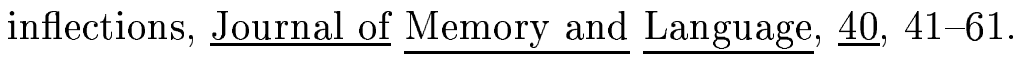

Baayen, R.H., Burani, C. \& Schreuder, R. (1996). Effects of semantic markedness in the processing of regular nominal singulars and plurals in Italian. In G.E. Booij \& J. van Marle (Eds.), Yearbook of Morphology 1996. Dordrecht: Kluwer.

Baayen, R.H., Dijkstra, T.\& Schreuder, R. (1997). Singulars and plurals in Dutch: Evidence for a parallel dual route model. Journal of Memory and Language, $\underline{37}, 94-117$.

Baayen, R.H., Piepenbrock, R., \& Gulikers, L. (1995). The CELEX lexical database (CD-ROM). University of Pennsylvania, Philadelphia, PA: Linguistic Data Consortium.

Baayen, R.H., Schreuder, R., de Jong, N.H. \& Krott, A. (2002). Dutch inflection: The rules that prove the exception. To appear in: S. Nooteboom, F. Weerman, \& F. Wijnen (Eds.), Storage and computation in the language faculty. Dordrecht: Kluwer Academic Publishers, pp. 61-92.

Bertram, R., Laine, M., Baayen, R.H., Schreuder, R., \& Hyönä, J. (1999). Affixal homonymy triggers full-form storage even with inflected words, even in a morphologically rich language. Cognition, 74, B13-B25.

Bertram, R., Schreuder, R., \& Baayen, R.H. (2000). The balance of storage and computation in morphological processing: the role of word formation type, affixal homonymy, and productivity. Journal of Experimental Psychology: Memory, Learning, and Cognition 26, $419-511$.

Booij, G.E. (1993). Against split morphology. In G.E. Booij \& J. van Marle (Eds.), 
Yearbook of Morphology 1993 (pp. 27-49). Dordrecht: Kluwer.

Butterworth, B. (1983). Lexical representation. In B. Butterworth (ed.), Language production, Vol. II (pp. 257-294). London: Academic Press.

Bybee, J. (2001). Phonology and language use. Cambridge: Cambridge University Press.

Caramazza, A., Laudanna, A. \& Romani, C. (1988). Lexical access and inflectional morphology. Cognition, $\underline{28}, 297-332$.

Clahsen, H. (1999). Lexical entries and rules of language: A multidisciplinary study of

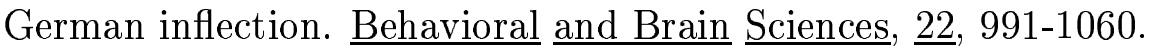

Clahsen, H., Eisenbeiss, S. \& Sonnestuhl, I. (1997). Morphological structure and the processing of inflected words. Theoretical Linguistics, $\underline{23}$, 201-249.

Giraudo, H. \& Grainer, J. (2001). Priming complex words: Evidence for supralexical representation of morphology. Psychonomic Bulletin \& Review, $\underline{8}$, 96-101. Grainger, J. \& Jacobs,

A.M. (1996). Orthographic processing in visual word recognition: A multiple read-out model. Psychological Review, 103, 518-565.

Grainger, J. \& Segui, J. (1990). Neighborhood frequency effects in visual word recognition: A comparison of lexical decision and masked identification latencies. Perception \& Psychophysics, $\underline{47}, 191-198$.

Hasher, L. \& Zacks, R. T. (1984). Automatic processing of fundamental information. The case of frequency of occurrence, American Psychologist, $\underline{39}, 1372-$-1388.

Laudanna, A. \& Burani, C. (1985). Address mechanisms to decomposed lexical entries. 
$\underline{\text { Linguistics, }} \underline{23}, 775-792$.

Laudanna, A. \& Burani, C. (1995). Distributional properties of derivational affixes: Implications for processing. In L.B. Feldman (Ed.), Morphological aspects of language processing (pp. 345-364). Hillsdale, NJ: Erlbaum.

Marcus, G. F., Brinkmann, U., Clahsen, H., Wiese, R., \& Pinker, S. (1995). German inflection: The exception that proves the rule. Cognitive Psychology, 29, 189-256.

Marslen-Wilson, W.D. (1987). Functional parallelism in spoken word-recognition. Cognition, $\underline{25}, 71-102$.

Norris, D.G. (1994). Shortlist: A connectionist model of continuous speech recognition. $\underline{\text { Cognition, }} \underline{52}, 189-234$.

Pinker, S. (1999). Words and Rules: The Ingredients of Language. London: Weidenfeld and Nicolson.

Schriefers, H., Zwitserlood, P. \& Roelofs, A. (1991). The identification of morphologically complex spoken words: Continuous processing or decomposition? Journal of Memory and Language, $\underline{30}, 26-47$.

Sereno, J.A. \& Jongman, A. (1997). Processing of English inflectional morphology. Memory $\underline{\& \text { Cognition, }} \underline{25}, 425-437$.

Sonnenstuhl, I. \& Huth, A. (2002). Processing and representation of German -n plurals: a dual mechanism approach. To appear in Brain and Language.

Taft, M. (1979). Recognition of affixed words and the word frequency effect. Memory \& Cognition, 
$\underline{7}, 263-272$.

Taft, M. (1988). A morphological- decomposition model of lexical representation. Linguistics, $\underline{26}, 657-667$.

Taft, M. (1994). Interactive- activation as a framework for understanding morphological processing. Language and Cognitive Processes, $\underline{9}$, 271-294.

Tyler, L.K., Marslen-Wilson, W., Rentoul, J. \& Hanney, P. (1988). Continuous and discontinuous access in spoken word-recognition: The role of derivational prefixes. Journal of Memory and Language, $\underline{27}, 368-381$. 


\section{Author Notes}

We would like to thank Femke van der Weide, Pieter Meima and Leonore Biegstraaten for their assistance with this research. The first author was supported by the Dutch National Research council NWO (PIONIER grant). Please address correspondence to R. Harald Baayen, Interfaculty Research Unit for Language and Speech, University of Nijmegen, Wundtlaan 1, 6525 XD Nijmegen, The Netherlands, or by e-mail to harald.baayen@mpi.nl. 


\section{Footnotes}

1. Dutch singular nouns with a lax vowel and single consonant in their final syllable (e.g., kat, cat) are written with a doubled consonant in the plural (e.g., katten, cats). Furthermore, singular nouns with a tense vowel and single consonant in their final syllable (e.g., boom, tree) are written with a double vowel in the singular, but with a single vowel in the plural (e.g., bomen, trees). Although these are highly consistent rules in Dutch orthography, word pairs with these spelling alternations were avoided in Experiment 1. 
Appendix A

Words used in Experiments 1 and 2: RTs in auditory lexical decision are given for the singular and plural form, followed by the corresponding RTs in visual progressive demasking. Note that pond and pont were not used in the auditory experiment, while front and zeis were not used in the progressive demasking experiment.

High Stem Frequency, plural dominant

darm (intestine) 8199151617 1983; dier (animal) 7307391702 1666; duin (dune) 871887 1750 1971; eend (duck) 7367361490 1579; fout (mistake) 8808301452 1680; gast (guest) 7828381627 1340; heup (hip) 7898451194 1625; kaars (candle) 7747451600 1627; klant (customer) 7066921698 2115; long (lung) 7788031949 1857; maand (month) 9298421523 1990; mens (human) 7598111528 1607; mouw (sleeve) 7798851579 1953; norm (standard) 8419361981 1725; plank (plank) 7227351465 2212; rots (rock) 8858442063 1857; term (term) 8658371904 2126; voet (foot) 7117831621 1708; wand (wall) 8059951365 2106; wang (cheek) 7717541489 1368; wolk (cloud) 8519011534 1813; woord (word) 787900 1586 1873; zenuw (nerve) 8549761505 1783; zuil (pillar) 93190924952014.

High Stem Frequency, singular dominant

ambt (office) 95110531610 2449; buik (stomach) 7269441722 2261; drank (drink) 777880 1762 1906; eeuw (century) 7258431403 1839; feit (fact) 10158941786 1549; front (front) 10641020 - - ; gang (passage) 8387821033 1502; helft (half) 9039092045 2133; hemd (shirt) 7839451481 1954; hoofd (head) 7598421453 1925; huid (skin) 8359461668 2244; kast (cupboard) 6437661679 1706; kern (core) 7378531825 2610; nest (nest) 7918762111 1937; park (park) 7598171399 2354; plein square 7618031889 1999; pond (pound) - - 1257 2061; soep (soup) 73611321348 1546; stijl (style) 88711862184 2598; tijd (time) 685752 
1612 1710; tong (tongue) 6747241499 2062; voogd (guardian) 102696715812290.

Low Stem Frequency, plural dominant

berk (birch) 10399391680 2054; biet (beet) 8638282042 1681; dwerg (gnome) 721805 1341 1709; erwt (pea) 8118311980 1709; flank (flank) 9289571818 2163; friet (chips) 826 9091830 1726; geit (goat) 8778251574 1778; gift (gift) 8479662059 1671; halm (stalk) 8928421869 2540; kers (cherry) 7617532055 1812; klomp (clog) 7799481325 1806; kluit (lump) 7708522599 2406; kous (stocking) 8217601275 1656; kuit (calf) 7987672779 2406; lakei (lackey) 8258771947 2242; meeuw (sea-gull) 7848591744 1460; nier (kidney) 803817 1720 2146; rups (caterpillar) 7668221861 1653; twijg (twig) 88110361634 2127; welp (cub) 9208991826 1837; wesp (wasp) 835855959 1258; wilg (willow) 8668402194 2010; worm (worm) 87093112952002.

Low Stem Frequency, singular dominant

baai (bay) 97810472246 2403; boeg (bow) 7879041450 1755; bruid (bride) 9169391607 2391; fuik (fyke) 93810632262 2020; galg (gallows) 9339371449 2069; havik (goshawk) 8879711651 1619; kelk (goblet) 8619051866 2598; klerk (clerk) 7608962468 2419; korps (corps) 8489921639 2251; loep (loupe) 82310492112 2539; lont (fuse) 92610322040 2601; muil (mouth) 7409842575 2416; muts (hat) 6908131582 2064; part (part) 82910082280 1922; pont (ferry) - - 1775 2806; prei (leek) 7329861902 2179; pruik (wig) 7767801643 2158; romp (trunk) 93111641819 2056; sprei (spread) 106110971742 2471; stoet (procession) 8589702010 1999; telg (descendant) 9068981610 2078; valk (falcon) 8489032451 2262; vork (fork) 9068851597 2174; zalm (salmon) 8248871862 1806; zeis (scythe) 9571331 - -; zeug (sow) 923100914761901. 
Appendix B

Words used in Experiments 3 and 4: RTs in auditory lexical decision are given for the singular and plural form, followed by the corresponding RTs in visual lexical decision.

Plural dominant nouns

bretel (braces) 962760 - -; cijfer (number) 910992564 532; dadel (date) 889967632581 ; distel (thislte) 917943628 628; enkel (ankle) 803778519 602; knokkel (knuckle) 877829 605 625; krekel (cricket) 861806584 593; kruimel (crumb) 804864531 551; letter (letter) 774729563 547; meubel (piece of furniture) 818818506 517; nagel (nail) 947877525549 ; oksel (armpit) 731802571 609; rafel (frayed end) - - 683 660; rimpel (wrinkle) 915858580 553; schilfer (scale) 1008984 - -; stoppel (stubble) 1013914642 653; tegel (tile) 781784534 539; veter (lace) 965846590 570; vezel (fibre) 923910572 586; wervel (vertebra) 8791018 599 590; wimper (eyelash) 762870613551

Singular dominant nouns

anker (anchor) 728881540 562; beugel (brace) 888845542 510; bezem (broom) 851933 533 574; buidel (purse) 866872656 660; gondel (gondola) 8761012612 647; gordel 842875 545 573; haven (harbour) 9161027540 548; kerker (jail) 920897584 651; koffer (suitcase) 730747514 515; ladder (ladder) 786749527 569; luifel (awning) 941950635 676; monster (monster) 803907536 540; oven (oven) 772954517 542; pantser (armour) 905919636783 ; polder (polder) 807832555 570; richel (ledge) 851909650 611; schakel (link) 9511022570 577; spatel (spatula) 10371103626 644; stakker (wretch) - - 590 589; trechter (chute) 722 815634 693; zwager (brother-in-law) 10021025575648. 
Appendix C

Words used in Experiments 5 and 6: RTs in auditory lexical decision are given for the singular and plural form, followed by the corresponding RTs in visual progressive demasking.

Nouns

arts (doctor) 719.75785 .001464 .621519 .08 ; boot (boat) 887.17 - 1376.67 1724.27; burcht (castle) 933.27 - 1613.46 1823.08; cel (cell) - - 1385.46 1663.31; dorp (village) 834.33 831.56 1248.42 1323.50; dwerg (dwarf) 758.91959 .451375 .001414 .42 ; fornuis (stove) 953.00 1557.54 1659.31; gang (corridor) 814.64913 .301271 .92 1431.46; geest (ghost) 947.331115 .00 1526.69 1643.54; gitaar (guitar) 748.55 999.91 1625.62 1731.62; held (hero) 842.33 - 1351.46 1577.92; hemd (shirt) 863.36 - 1371.54 1492.38; hert (doe) 836.09808 .001703 .54 1945.85; hut (hut) 674.91897 .001748 .691809 .85 ; jurk (dress) 853.10 - 1610.42 1494.08; kasteel (castle) 709.00962 .101609 .851696 .77 ; kraan (tap) 854.25 - 1531.62 1702.15; kruik (jar) 919.90 1907.83 1951.67; lamp (lamp) 775.75 - 1303.77 1201.17; mast (mast) 926.18 - 1334.001669 .00 ; mos (moss) 898.90 - 1525.23 2026.33; orkest (orchestra) 824.73913 .901544 .54 1678.54; paus (pope) 847.55834 .821433 .001885 .25 ; sigaar (sigar) 857.42937 .001369 .921584 .31 ; stronk (trunk) 995.00 - 1862.461864 .92 ; vork (fork) 865.081053 .331417 .831807 .08$.

Verbs

blonk (shone) 890.11 - 1433.001881 .15 ; droeg (carried) 710.08791 .501588 .31 1496.69; dwong (forced) 870.27802 .801656 .69 1890.69; floot (whistled) 934.83952 .111612 .00 1650.38; gleed (slid) 1008.911067 .601671 .381666 .00 ; gold (counted) 899.36 - 1653.77 1804.77; hief (raised) 860.67 - 2046.77 1675.69; klom (climbed) 919.82 - 1719.00 2109.17; klonk (sounded) 848.42 858.901684 .77 1740.23; kromp (shrink) 881.25 939.501809 .92 2003.58; placht (used to) 
865.101019 .111718 .58 2046.46; rees (raised) 985.50 - 1981.091850 .55 ; sloeg (hit) 824.67 949.401532 .38 1449.54; slonk (shrink) 976.30 - 1992.31 1842.92; smeet (threw) 997.91 1110.701647 .83 1781.08; snoof (sniffed) 904.17 - 1696.69 1687.77; snoot (blew one's nose) 918.90 - 1783.002036 .54 ; ving (caught) 934.78 - 1491.58 1929.75; vlocht (braid) - 987.09 1748.69 1844.08; vloog (flew) 866.17 1077.921570 .69 1645.46; vroor (froze) - 1288.001885 .85 1995.50; wierp (threw) $758.251044 .671553 .92 \quad 1837.17$; zocht (searched) 871.27778 .80 1776.62 1574.77; zong (sang) 966.89851 .671240 .69 1415.33; zonk (sunk) 902.00895 .67 1555.08 1611.08; zwierf (wandered) 833.92 914.36 1683.46 1838.00. 
Table 1

$\underline{\text { Mean Latencies (in Milliseconds) and Percentages of Errors (within parentheses) }}$

for -en Noun Singulars and Plurals in Experiment 1 by items (Auditory Lexical Decision).

\begin{tabular}{llllllr}
\hline Stem Frequency & Dominance & \multicolumn{2}{c}{ Singular } & \multicolumn{2}{c}{ Plural } & Latency Difference \\
\hline \hline High & SgDom & 814 & $(6)$ & 902 & $(13)$ & 88 \\
High & PlDom & 807 & $(7)$ & 840 & $(7)$ & 33 \\
\hline Low & SgDom & 866 & $(9)$ & 978 & $(29)$ & 112 \\
Low & PlDom & 839 & $(10)$ & 867 & $(12)$ & 28 \\
\hline
\end{tabular}


Table 2

$\underline{\text { Mean Latencies (in Milliseconds) and Percentages of Errors (within parentheses) }}$

for -en Noun Singulars and Plurals in Experiment 2 by items (Progressive Demasking).

\begin{tabular}{llllllr}
\hline Stem Frequency & Dominance & \multicolumn{2}{c}{ Singular } & \multicolumn{2}{c}{ Plural } & Latency Difference \\
\hline \hline High & SgDom & 1635 & $(2)$ & 2030 & $(2)$ & 395 \\
High & PlDom & 1655 & $(1)$ & 1816 & $(1)$ & 161 \\
\hline Low & SgDom & 1885 & $(3)$ & 2198 & $(2)$ & 313 \\
Low & PlDom & 1800 & $(3)$ & 1885 & $(2)$ & 85 \\
\hline
\end{tabular}


Table 3

$\underline{\text { Mean Latencies (in Milliseconds) and Percentages of Errors (within parentheses) }}$

for -s Noun Singulars and Plurals in Experiment 3 by items (Auditory Lexical Decision).

\begin{tabular}{lccccc}
\hline Dominance & \multicolumn{2}{c}{ Singular } & \multicolumn{2}{c}{ Plural } & \multicolumn{2}{c}{ Latency Difference } \\
\hline \hline SgDom & 860 & $(3)$ & 914 & $(3)$ & 54 \\
PlDom & 877 & $(3)$ & 868 & $(2)$ & -9 \\
\hline
\end{tabular}


Table 4

$\underline{\text { Mean Latencies (in Milliseconds) and Percentages of Errors (within parentheses) }}$

for -s Noun Singulars and Plurals in Experiment 4 by items (Visual Lexical Decision).

\begin{tabular}{lllllr}
\hline Dominance & \multicolumn{2}{c}{ Singular } & \multicolumn{2}{c}{ Plural } & \multicolumn{2}{c}{ Latency Difference } \\
\hline \hline SgDom & 577 & $(2)$ & 604 & $(2)$ & 27 \\
PlDom & 582 & $(2)$ & 581 & $(1)$ & -1 \\
\hline
\end{tabular}


Table 5 Mean Latencies (in Milliseconds) and Percentages of Errors (within parentheses) for -en Noun and Verb Singulars and Plurals in Experiment 5 by items (Auditory Lexical Decision).

\begin{tabular}{lcrrrr}
\hline Word Category & \multicolumn{2}{c}{ Singular } & \multicolumn{2}{c}{ Plural } & Latency Difference \\
\hline \hline Nouns & 846 & $(8)$ & 924 & $(31)$ & 78 \\
Verbs & 893 & $(11)$ & 961 & $(28)$ & 68 \\
\hline
\end{tabular}


Table 6 Mean Latencies (in Milliseconds) and Percentages of Errors (within parentheses)

for -en Noun and Verb Singulars and Plurals in Experiment 6

by items (Progressive Demasking).

\begin{tabular}{lrrrrr}
\hline Syntactic Category & \multicolumn{2}{c}{ Singular } & \multicolumn{2}{c}{ Plural } & Latency Difference \\
\hline \hline Nouns & 1503 & $(1)$ & 1666 & $(2)$ & 163 \\
Verbs & 1682 & $(2)$ & 1781 & $(4)$ & 99 \\
\hline
\end{tabular}




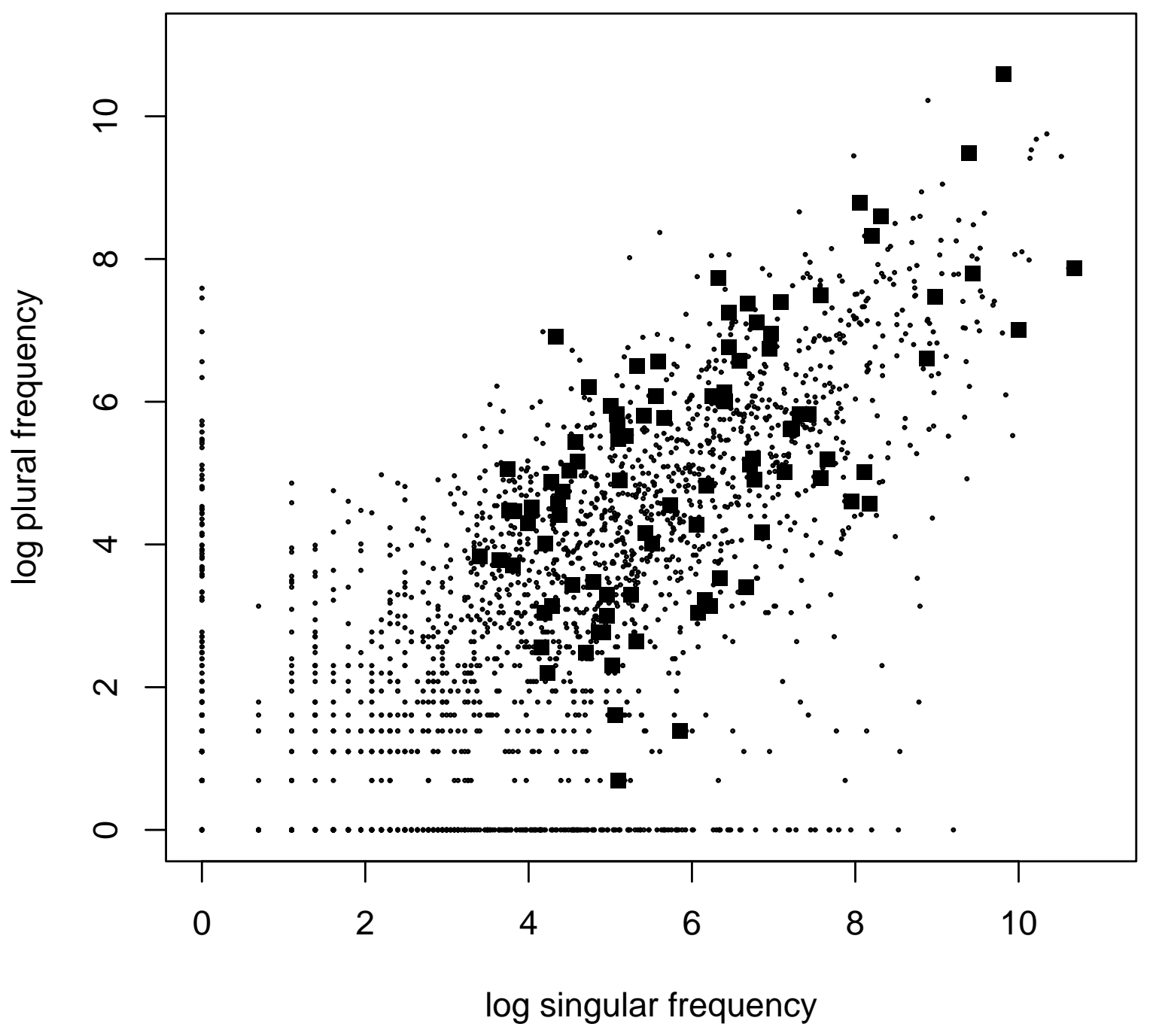




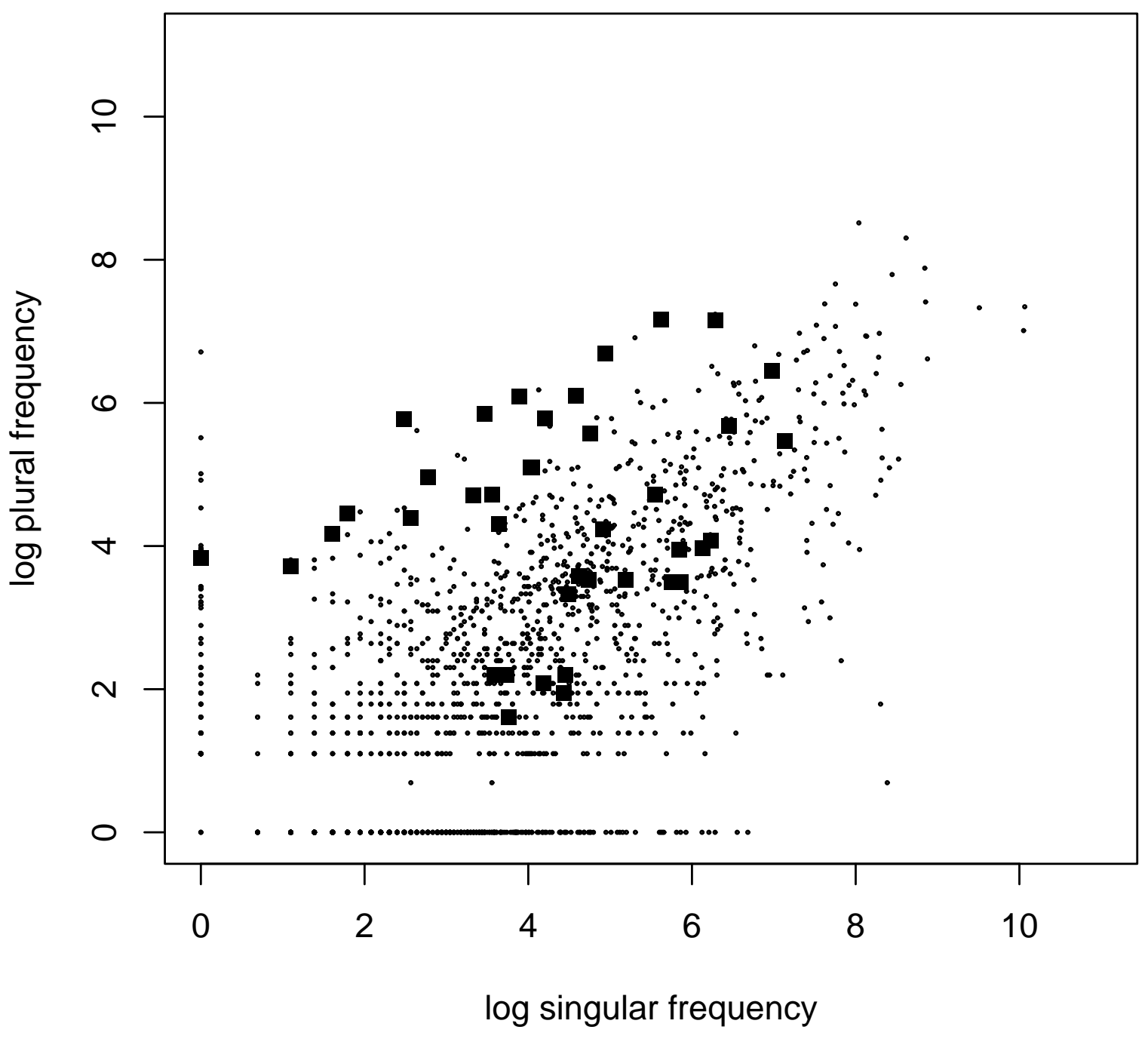


Figure 1. Monomorphemic nouns taking the -en plural in the plane spanned by log singular frequency and log plural frequency. The black squares highlight the materials of Experiment 1.

Figure 2. Monomorphemic nouns taking the $\underline{-\underline{s}}$ plural in the plane spanned by log singular frequency and log plural frequency. The black squares highlight the materials of Experiment 3 . 